\title{
A diathesis-stress model of chronic pain and disability following traumatic injury
}

\author{
Dennis C Turk PhD
}

DC Turk. A diathesis-stress model of chronic pain and disability following traumatic injury. Pain Res Manage 2002;7(1):9-19.

One of the perplexing features of pain is the wide variability in patients' responses to ostensibly the same extent of physical pathology. A range of cognitive, affective and behavioural factors are related to the perception of pain, maintenance of pain and disability, exacerbation of pain and response to treatment. Moreover, there is some evidence that individual differences and prior learning history also have a significant influence on the experience of pain and related disability. The role of these psychological factors in the maintenance of disability following traumas such as motor vehicle accidents and work-related injuries has generated considerable interest. This paper provides a brief overview of a set of predisposing factors, cognitive processes and behavioural principles that appear to be particularly important in the maintenance of disability following trauma. In particular, anxiety sensitivity, anticipation and avoid- ance of fear or harm, catastrophizing ideation, causal attributions for symptoms, self-efficacy and operant conditioning are discussed. Each of these factors is integrated in a diathesis-stress model that emphasizes the interaction of predisposing factors with a trauma, setting in motion a cascade of interpretive cognitive processes and reinforcement contingencies that maintain disability following the trauma. This model proposes a sequential process to explain the variation observed among people following a relatively minor trauma. The model is intended to be heuristic. It may be a useful conceptualization that can serve to guide prevention efforts and the development of treatment interventions.

Key Words: Anxiety; Beliefs; Catastrophizing; Causal attributions; Diathesis-stress; Fear or harm operant conditioning; Pain avoidance; Self-efficacy 


\section{Douleur chronique et incapacité par suite d'un traumatisme : modèle diathésique de stress}

RÉSUMÉ : Un des éléments de la douleur qui laissent les chercheurs perplexes est la grande variété de réactions manifestes à une même lésion physique. Une foule de facteurs cognitifs, affectifs et comportementaux interagissent avec la perception de la douleur, sa persistance et l'incapacité qu'elle entraîne, son exacerbation et les réactions au traitement. De plus, des données indiquent que les différences individuelles et les apprentissages passés exerceraient une forte influence sur l'expérience de la douleur et l'incapacité qui en résulte. Le rôle de ces facteurs psychologiques sur la persistance de l'incapacité par suite d'un traumatisme comme un accident d'automobile ou un accident de travail a suscité énormément d'intérêt. Le présent article donne un aperçu des facteurs favorisants, des processus cognitifs et des principes comportementaux qui semblent jouer un rôle particulièrement important dans la persistance de l'incapacité par suite d'un traumatisme. Font ici notamment l'objet de discussion l'anxiété, la sensibilité, l'anticipation et la crainte de la douleur, le comportement de fuite, les idées effrayantes, l'attribution causale des symptômes, l'auto-efficacité et le conditionnement opérant. Chacun de ces facteurs est intégré dans un modèle diathésique de stress qui met en évidence les interactions des facteurs prédisposants avec le traumatisme, qui déclenchent une réaction en chaîne de processus cognitifs interprétatifs et de mesures de renforcement qui, à leur tour, entretiennent l'incapacité par suite d'un traumatisme. Le modèle, de nature heuristique, tente d'établir un processus séquentiel de réactions visant à expliquer les variations observées entre les personnes à la suite d'un traumatisme relativement léger. Le modèle peut s'avérer utile pour orienter les efforts de prévention et l'élaboration d'interventions thérapeutiques.
$\mathrm{C}$ ronsider the case of a woman who is in an automobile accident. Her car is hit from behind while she is stationary at a stop sign. The vehicle that hits her is travelling at about $10 \mathrm{~km} / \mathrm{h}$. At first, she notes a sense of shock, followed by annoyance and finally concern. She notices that her heart is racing, her breath is shallow and she is shaking. She is worried about the symptoms that she is experiencing and begins to wonder whether she has been seriously injured. Initially, she feels only a little pain. The next morning, however, she awakens with a very stiff neck and dull pain radiating down her shoulders and arms. She notices that it hurts when she tries to move her head from side to side. She begins to worry about the pain and stiffness, concerned that she might have sustained a serious injury. As she thinks about the symptoms, her breathing becomes shallow again and she begins to tremble. She wonders whether all of these symptoms are related to her accident of the previous day.

She takes a hot shower but feels no better. She makes an appointment to see her family physician, who tells her that she has had a 'whiplash' injury, but he does not think that it is serious. To be cautious, however, he suggests that she have an $\mathrm{x}$-ray of her neck. The $\mathrm{x}$-ray is negative. The physician provides her with a soft cervical collar to wear for a week, prescribes some muscle relaxants, and tells her to take it easy and to avoid any activities that increase her pain. Her family members are concerned and solicitous. They give her extra attention, encourage her to rest and take over most of her household responsibilities.

When the symptoms persist for several weeks, despite the use of the collar, medication and avoidance of activity, the patient becomes quite anxious, fearing that her symptoms will persist and become worse. She also notices that when she removes the collar, movement of her neck is even more restricted and her pain is increased. Her family's concerns escalate because the symptoms do not seem to be getting any better. If anything, she is feeling increased stiffness and inability to rotate her neck. She finds that she is doing increasingly less because she is afraid that the activities will increase her pain and may even exacerbate her injury. She feels that there is nothing she can do to control the pain, and begins to fear that she will become a complete invalid.

When seen six months later, the patient has been to several specialists who have been unable to relieve her pain. She continues to wear the cervical collar, even though her physician has told her that she no longer needs to do so. Since her original contact with her family physician, she has been to several specialists but continues to suffer pain and restriction of movements. These physicians are perplexed. They order many diagnostic tests but none are conclusive. They continue to prescribe analgesic medication and passive physical therapy modalities. The patient has given up many activities and now spends most of her time at home alone sitting in a lounge chair worrying about her future and has become quite depressed. Her family feels frustrated, helpless and hopeless.

The scenario that has been described is not unique. A significant number of people who suffer from traumatic injuries have experienced a similar downward course. However, the majority of people with such relatively inconsequential injuries as those experienced by the patient described above have little functional limitation, with symptoms resolving within a few days. It is reasonable to ask, what differentiates those who return to functioning with minimal problems from those who respond like the patient described above? How can the differences between what contributes to these very different outcomes of ostensibly identical, relatively minor traumas be understood?

The first thought may be that the severity of physical pathology differentiates the patient described above from those who recover. Numerous studies have documented, however, that the relationship between physical pathology and disability is quite low, and that the amount of physical pathology is not a very good predictor of return to functioning (1-3). Another explanation may be that some preexisting psychopathology predisposed this patient to 


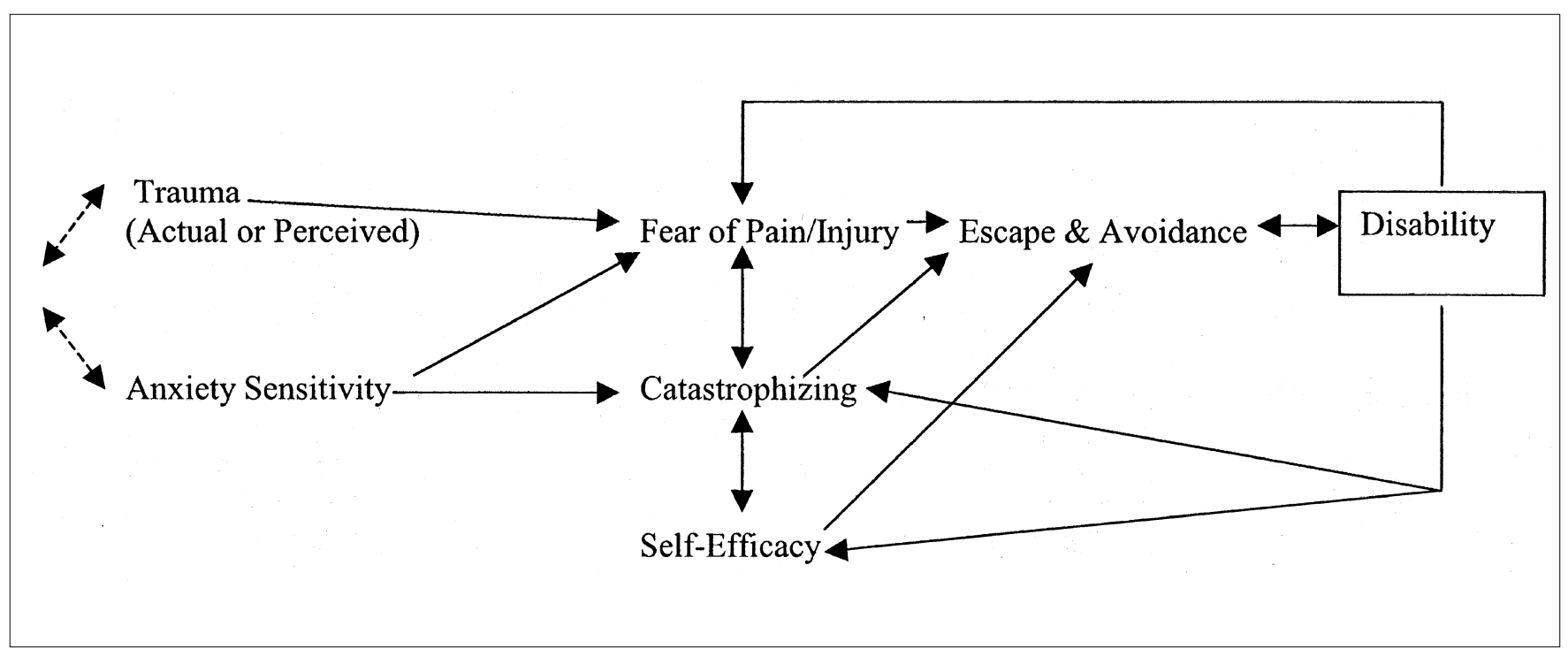

Figure 1) Diathesis-stress model of chronic pain and disability following trauma

become disabled. Although there is limited evidence supporting this hypothesis $(4,5)$, emotional distress and outright psychopathology do not appear to be sufficient to explain who is at risk for disability following a trauma (6). Moreover, successful treatment of physical pathology, in some instances, has been shown to reduce significantly or eliminate emotional distress in patients with persistent pain, suggesting that premorbid psychopathology is not an adequate explanation (7).

Over the past two decades, there has been a growing body of literature on the role of cognitive and behavioural factors in pain and pain-related disability $(8,9)$. For example, Burton et al (1) reported that measures of physical pathology during acute back problems accounted for only $10 \%$ of the variance in disability one year after seeking treatment. In contrast, psychosocial variables accounted for $59 \%$ of the variance in disability after one year. These studies do not suggest that psychological factors are the sole etiological factor but, rather, that they interact with physical pathology. Some of the factors that have been implicated in the development of chronicity and the maintenance of disability include anxiety sensitivity, anticipation of pain and injury, fear avoidance, causal attribution, catastrophizing, self-efficacy and operant conditioning. These concepts and constructs are described below.

One way to integrate these factors is within a diathesisstress model that takes into consideration both predisposing characteristics of people and an instigating event, such as a motor vehicle accident or an injury related to heavy lifting on the job, to explain the differences observed between people who, after exposure to a trauma, recover with limited residual effects and those, like the patient described above, who become chronically disabled. The diathesisstress model proposes that the impact of an initiating event is more likely to contribute to disability in people who interpret symptoms as indicative of serious problems; are preoccupied with bodily processes and are predisposed to respond with fear to the implications of perceived symptoms (eg, negative affectivity); and believe that the way to avoid exacerbation of pain and possibly further physical damage is to avoid activities that increase pain. These people are vulnerable and 'at risk' for the persistence of symptoms and disability.

These at risk people believe that all activities that cause increased symptoms or those that are anticipated to cause injury should be avoided. Failure to engage in activities believed to be harmful has several results. It prevents the pain sufferers from obtaining any corrective feedback or evidence that disconfirms their worry about reinjury; their physical conditioning is diminished; and increasing inactivity confirms their view of themselves as being disabled. Moreover, their perceived control over their symptoms is diminished, contributing to greater distress and disability. The avoidance of activity and feelings of limitations in functional activity are also reinforced by significant others, including health care providers, who continue the quest to identify the causes of the symptoms and recommend a plethora of treatments. The diathesis-stress model is depicted in Figure 1. In the present paper, the literature on the role of the psychological and behavioural variables that are listed above and incorporated into the proposed diathesis-stress model is reviewed.

\section{PREDISPOSITION - ANXIETY SENSITIVITY}

Anxiety sensitivity is the fear of anxiety symptoms based on the belief that they will have harmful consequences (10). Anxiety sensitivity appears to be a vulnerability factor (ie, diathesis, dispositional) that may condition specific fears that contribute to the development and maintenance of distress. 
From an evolutionary perspective, pain is essential for survival. Thus, attention may be primed to process painful stimuli ahead of other attention demands. People with high levels of anxiety sensitivity may be especially hypervigilant to pain and other noxious sensations. Selective attention directed toward threatening information such as bodily sensations leads to greater arousal. Because of this attention process, patients with high anxiety sensitivity may be primed such that minor painful stimuli may be amplified.

Anxiety sensitivity has been shown to be correlated with exaggerated fear responses. The unpleasantness of this exaggerated fear response can lead people with high anxiety sensitivity to behave in ways that reduce fear and anxietyrelated bodily sensations. Such behaviour often takes the form of avoidance to prevent exacerbation of symptoms and further injury.

Preliminary studies have reported the importance of anxiety sensitivity as a predisposing factor in chronic pain. Asmundson and Norton (11) found a positive association between anxiety sensitivity and pain-related anxiety, escape or avoidance behaviours, fear of negative consequences of pain and negative affect. Not only were patients with high anxiety sensitivity more likely to experience greater cognitive disturbances as a result of their pain, but they were also likely to use greater quantities of analgesic medication to control equal amounts of pain compared with patients with low or medium anxiety sensitivity. Further, Asmundson and Taylor (12) showed that anxiety sensitivity directly exacerbates fear of pain and indirectly exacerbates pain-specific avoidance behaviour, even after controlling for the direct influences of pain severity on these variables (13).

General fearful appraisals of bodily sensations may sensitize people at risk and cause elevated awareness of bodily sensations. Thus, anxiety sensitivity is only one individual difference characteristic that may predispose people to develop and maintain chronic pain and disability. For example, somatization, negative affectivity, bodily preoccupation and catastrophic thinking also may be involved (14). Vlaeyen et al (15) argued that a style of catastrophic thinking about pain might be a risk factor for the emergence of pain-related fear. Catastrophic thinking is discussed below. It is likely, however, that these individual difference constructs are interrelated and are not totally independent.

\section{COGNITIVE PROCESSES}

There is a growing body of evidence showing that several sets of interrelated beliefs are of particular importance in understanding responses to pain. These include beliefs about the cause and meaning of symptoms, fear associated with anticipation of pain and injury resulting from activities, and perceptions of the ability or lack of ability to cope with pain and associated problems (self-efficacy). People are not usually aware of the presence and influence of such cognitive processes on their experience and behaviours. Pain-related beliefs have been found to be associated with psychological functioning $(16,17)$, physical functioning
$(17,18)$, coping efforts $(19,20)$, pain behaviours $(16,21)$ and response to treatment $(22,23)$.

\section{Anticipation of pain and injury}

As noted by Wall (24), the threat of intense pain captures the attention and is difficult to disengage from. Physical sensations are a constant reminder of a disease or injury and are capable of being interpreted or misinterpreted (25), leading to over-reaction and outright panic (26). Continual vigilance and monitoring of noxious stimulation, and the belief that it signifies disease progression, may render even low intensity nociception less bearable. The experience of pain may initiate a set of extremely negative thoughts and arouse fears of inciting more pain and injury, and of the future impact (27).

Crombez et al (28) reported that the threat of pain instigated preparatory responses and primed the attentional system for interruption by stimuli that shared sufficient features (ie, stimulus generalization) with the object of threat. Several studies have indicated that a person's past experiences with pain, the memory of that pain and the recurrent episodes of pain tend to sensitize the person to anticipate more pain, influence the amount of fear and maintain pain-avoidance behaviours (29).

Some people with chronic pain behave as if their pain is acute. They focus on their bodies in the desire to obtain more information. They are vigilant for any signs indicating further harm and are prepared to avoid or escape from any perceived physical threat. Fear avoidance may reflect the inability to shift one's attention away from the pain-related stimuli (30).

Several studies have found a strong association between pain-related fear and increased physiological arousal. Physiological arousal may contribute to the maintenance of pain and increase pain severity (31). Burns et al (32) and Vlaeyen et al (33) found that fear-induced increases in lower paraspinal muscle reactivity predicted greater pain during a subsequent physical performance test. No such association was found for other muscles.

People learn that the avoidance of situations and activities in which they have experienced acute episodes of pain reduces the likelihood of re-experiencing pain. Fear of pain and anticipation of pain are cognitive-perceptual processes that are not driven exclusively by the actual sensory experience of pain. Fear of pain and the anticipation of pain can exert a significant impact on the level of function and pain tolerance $(33-35)$. Several investigators $(3,15,36)$ have suggested that fear of pain, driven by the anticipation of pain and not by the sensory experience of pain itself, is a strong negative reinforcement for the persistence of avoidance behaviour and the alleged functional disability in patients with chronic low back pain.

Avoidance behaviour is reinforced in the short term, through the reduction of suffering associated with nociception (37). Avoidance, however, can be a maladaptive response if it persists and leads to increased fear, limitation in activity, physical and psychological consequences that contribute to disability, and persistence of pain in the 
absence of identifiable organic pathology. A growing number of studies have shown that fear of movement and fear of (re)injury are better predictors of functional limitations than biomedical parameters. McCracken et al (37) observed greater fear to correspond with higher levels of pain and greater restriction of range of motion in people with back pain who were asked to perform a passive straight legraising task. Crombez et al (38) showed that patients who avoided activity reported significantly higher levels of fear of movement and significantly lower levels of performance on a maximal performance task than those who were more active. Crombez et al (38) found a significant association between physical performance level and pain-related fear, but no relationship between performance and pain intensity. In a replication, Crombez et al (39) showed that painrelated fear was the best predictor of behavioural performance in trunk extension and flexion, and weight-lifting tasks, even after partialling out the effects of pain intensity. Finally, Vlaeyen et al (40) showed that the fear of movement or (re)injury was the best predictor of the patient's self-reported disability among patients with chronic back pain and that physiological sensory perception of pain and biomedical findings did not add any predictive value.

Health care providers may inadvertently contribute to disability by recommending additional diagnostic testing and treatment (41). Mayer and Gatchel (42), and Hildebrandt et al (43) argued that patients with chronic back pain often demonstrate prolonged iatrogenically encouraged protectiveness and passivity, mostly induced by fear, which eventually leads to a decrease in spinal mobility, muscle strength and cardiovascular fitness.

Prospective studies also support the central role of fear on pain and disability. Waddell et al (3) found that fearavoidance beliefs concerning work were strongly related to disability levels one year after an initial injury, more so than biomedical variables and characteristics of pain. They postulated that those who fear pain avoid pain-inducing activities or activities that are expected to produce pain, thereby gaining weight, losing mobility and strength, and eventually becoming chronic sufferers. According to Waddell et al (3), "fear of pain and what we do about it is more disabling than the pain itself". Similar results were reported by Klenerman et al (44), who studied patients with acute back pain in primary care settings. They found that a set of psychological variables (including fear avoidance) were the most powerful predictors of chronic disability.

Linton et al (14) showed that asymptomatic people who had high scores on a measure of fear-avoidance had twice the risk of suffering an episode of back pain and a 1.7 times higher risk of lowered physical functioning one year after assessment than those with low scores. These data suggest that fear-avoidance beliefs may be involved at a very early point in the development of pain and associated activity problems in people with back pain.

Himmelstein et al (45) and Mathis et al (46) found that patients who could not work because of occupationalrelated upper extremity disorders reported higher levels of pain and fear of pain, and a greater tendency to catastrophize than those who could work. Klenerman et al (44) conducted a longitudinal study of patients with back pain and found that fear avoidance predicted low back trouble 12 months later. Qualitative studies in primary care have also noted the avoidance of activities owing to fear of pain in acute populations $(47,48)$. Crombez et al $(38)$ observed that approximately two-thirds of people suffering from chronic, nonspecific low back pain avoided back straining activities because of fear of (re)injury. In addition, they found that these patients were very alert to back sensations.

Al-Obaidi et al (49) found that anticipation of pain and fear-avoidance beliefs about physical activity significantly predicted variation in the spinal isometric strength deficit. Pain during testing and answers to a disability belief questionnaire were not related. Thus, anticipation of pain and the fear-avoidance belief about physical activities were the strongest predictors of the variation in physical performance. Similarly, Keen et al (50) found that avoidance of physical activity and fear of pain returning were the two main factors associated with people with acute back pain reducing their physical activity, even though the majority believed strongly that being physically active helped to ease their back pain. The crucial components that linked physical activity and the way that subjects perceived and behaved with their low back pain were fear of pain returning and avoidance of activity. Finally, McCracken and Gross (51) reported that a reduction in pain-related anxiety predicted improvement in functioning on affective distress, pain and pain-related interference with activity. Thus, it appears that fears, pain-related anxiety and concerns about harm avoidance all play an important role in chronic pain, and that these factors need to be assessed and addressed within treatments provided to patients with chronic pain.

The validity of fear avoidance has been shown by preliminary treatment outcome studies. For people suffering from excessive fears, counterconditioning of fear by means of graded exposure to the feared stimulus has proved to be the most effective treatment (52). Several investigators have shown the effectiveness of exposure-based, counterconditioning treatments for secondary prevention of chronicity for people with subacute, work-related back pain (53). Furthermore, there is some provocative evidence that exposure-based, counterconditioning treatment focusing on fear of movement can be effective for patients with chronic back pain $(15,54)$.

Negative affect may amplify pain-related fear for chronic pain sufferers; therefore, there is a reciprocal relationship with pain-related fear exacerbating negative affect and negative affect increasing pain-related fear. This relationship is most pronounced in people who are already predisposed by high degrees of anxiety sensitivity.

In summary, anticipation of pain in pain populations often results in poor behavioural performance that cannot be accounted for by pain severity alone $(28,37)$. When a patient with pain symptoms is exposed to the feared situation (eg, activity), there is a cascade of responses, including a cogni- 
tive response (eg, worry) (55), effort to escape and avoid increased pain and exacerbation of injury $(15,38,39,56)$, and self-reported disability (56). Fearful patients appear to attend more to possible signals of threat and be less able to turn their attention away from pain-related information $(38,57)$.

\section{Catastrophizing}

There is some disagreement regarding the mechanisms underlying the process of catastrophizing. Some view catastrophizing as a coping strategy, whereas others tend to view it as a maladaptive way of thinking. Because the latter view confounds the process with the outcome, in the present article, catastrophizing is viewed as a method of cognitively coping with pain and is characterized by negative self-statements, and overly negative thoughts and ideas about the future. Investigators $(15,33,58,59)$ have shown that cognitive factors play an important role in many aspects of the experience of and responses to chronic pain. Moreover, these factors are important in predicting pain disability $(1,14,44,56)$. For example, it has been determined that catastrophizing is a significant predictor of pain, disability, and physician visits for both patients with chronic back pain and those with rheumatoid arthritis (58). Interestingly, physical factors did not significantly predict any of these variables. Burton et al (1) found, in a prospective study, that catastrophizing was the most powerful predictor of back pain chronicity, almost seven times more important than the best of the clinical and historical variables.

Several studies have shown that a reduction in catastrophizing was associated with less pain and improved psychological functioning following cognitive-behavioural or operant behavioural treatment for low back pain (60). Flor et al (61) found that patients who improved following treatment showed a reduction in catastrophizing, whereas those who did not improve failed to reduce their levels of catastrophizing.

Vlaeyen and colleagues (40) suggested that catastrophizing in relation to pain promotes fear of movement or (re)injury that, in turn, leads to avoidance behaviour, disuse and disability. They proposed that patients who engage in catastrophic thinking may develop fear and anxiety concerning movements, and avoid movements that they believe may be painful. Thus, they may not recover normal movement that would promote healing and, consequently, become more physically limited and depressed.

\section{Causal attributions}

Turk and Holzman (62) suggested that fear-avoidance beliefs might be an especially important issue when patients attribute the original cause of their pain to a sudden, traumatic injury. Patients may fear that they are seriously injured when they have been in a traumatic accident, may fear for the future and eventual recovery, and may fear that activities will exacerbate their physical injury (39).

Cognitive mechanisms of symptom perception in patients with chronic pain may be affected by beliefs of having been 'injured' (associated with the traumatic onset) and that activity will lead to additional harm and symptom exacerbation. Thus, the acknowledgement that symptoms followed a trauma appears to increase fear greatly. For example, preoccupation with bodily symptoms is commonly observed among patients, such as the patient described in the present article, who have been involved in motor vehicle accidents (63). Such hypervigilance may predispose patients to selectively attend to all somatic perturbations that might otherwise be ignored and to avoid activities that they believe will contribute to further problems (ie, fear avoidance). Moreover, exposure to physical trauma may alter one's interpretation of physical sensations, such that any physical sensation is interpreted as abnormal, harmful and noxious, thereby increasing anxiety. These changes may consequently lower pain threshold and tolerance, increase activity avoidance and facilitate general deconditioning.

Experiencing a traumatic injury may also alter how people evaluate sensory information. For example, pain perception and sensitivity may be altered by involvement in an accident. Lee et al (64) observed that, following a motor vehicle accident, victims reported lower pain tolerance compared with healthy controls. It is not known whether decreased pain tolerance among post-trauma patients is due to subtle, if not gross, changes in physiology, resulting in hypersensitivity to pain due to changes in psychological processes involving selective attention, fear appraisals or both. As noted, elevated body awareness and anticipation of pain may result in a pain-sensitive perceptual system in which one focuses on physical sensations and interprets relatively benign sensory input as pain. Some people may be predisposed to hypervigilance and fear avoidance based on high levels of anxiety sensitivity, negative affectivity or both.

A substantial number of patients with diverse chronic pain syndromes attribute the onset of their pain to some type of trauma. In a sample of patients with chronic pain, $75 \%$ of a heterogeneous sample and $50 \%$ of a sample of patients with fibromyalgia attributed the onset of their symptoms to a physical trauma, most commonly a motor vehicle accident or work-related injury $(41,65)$. When a standardized system for evaluating physical pathology was used, no significant differences were found in the physical findings between the groups who reported a traumatic onset and those who reported an insidious onset with unknown cause. Patients who attributed their pain to a specific trauma reported significantly higher levels of emotional distress, life interference and pain severity than did the patients who indicated that their pain had an insidious onset, despite the lack of differences in physical pathology identified between these groups.

Interestingly, it was also found that patients who attributed symptoms to a physical trauma were significantly more likely to receive physical treatments for symptoms, including nerve blocks, physical therapy and transcutaneous electrical nerve stimulation, than those who did not $(41,65)$. These patients with traumatic-onset pain were five times more likely to be prescribed opioid medication, even though they did not reveal greater physical pathology, than 
patients with nontraumatic onset of pain. Thus, patients who reported a traumatic onset to their symptoms, independent of objective indications of physical pathology, were treated differently by physicians. In another study (65), physicians were observed to be more likely to prescribe opioid medication based on the patients' reports of disturbed mood, greater impact on their lives and behavioural presentation, but not based on physical pathology or even reported pain severity. The role of physician behaviour in the maintenance of symptoms and disability of pain sufferers has frequently been noted $(66,67)$.

The attribution of pain and related symptoms to a physical trauma seems to add an additional burden and to exacerbate the problems of patients with chronic pain. In addition, patients whose painful symptoms follow an accident have been shown to be more refractory to treatment than patients with nontraumatic onset of pain $(68,69)$.

\section{Self-efficacy}

The construct of self-efficacy has gained a great deal of attention in the pain literature (70). A self-efficacy expectation is defined as a personal conviction that one can successfully perform certain required behaviours in a given situation. Bandura (71) proposed that, given sufficient motivation to engage in a behaviour, it is a person's self-efficacy beliefs that determine whether that behaviour will be initiated, how much effort will be expended, and how long the effort will be sustained in the face of obstacles and aversive experiences. From this perspective, coping behaviours are conceptualized as mediated by peoples' beliefs that situation demands do not exceed their coping resources. Those with weak efficacy expectancies are viewed as less likely than those with strong expectancies to emit coping responses or persist in the presence of obstacles and aversive consequences.

Mastery experiences gained through performance accomplishments are hypothesized to have the greatest impact on establishing and strengthening expectancies because they provide the most information about actual capabilities. Thus, techniques that enhance mastery experiences (eg, graded task accomplishments with both physical and verbal feedback) will, according to Bandura (71), be powerful tools for bringing about behavioural change. Moreover, the patient's self-attribution of task accomplishment should enhance maintenance of improvement (72). If patients feel that there is little that they can do to control any of their symptoms, they will expend minimal effort in trying to use self-control techniques and may become more emotionally distressed, which in turn, may amplify the symptom being experienced.

Converging lines of evidence from investigations of both laboratory and clinical pain indicate that perceived selfefficacy operates as an important cognitive factor in the control of pain $(73,74)$, adaptive psychological functioning (75), disability (76), impairment (77) and treatment outcome (76). For example, Jensen and colleagues $(73,74)$ found that improved functioning and decreased health care use were associated with changes in both beliefs and cognitive coping strategies. However, the relationship between change in behavioural coping strategies after treatment (ie, exercise, relaxation, decreases in pain contingent rest, medication) and changes in exercise programs and the use of rest was extremely weak. These changes in behaviour did not explain significant amounts of improvement. The authors concluded that

\section{the results suggest that improvement following multidisciplinary pain treatment may be more closely associated with changes in what patients think about their pain than with changes in what they do about their condition. (74)}

Research by Dolce et al (78) has focused on the important associations among concern about the performance of exercise, actual performance of exercise and self-efficacy in patients with back pain. Exercise quotas were shown to increase levels of previously avoided exercises. Additionally, when quotas were implemented, self-efficacy ratings were observed to increase, while patients' ratings of concern diminished. Self-efficacy expectancies were found to closely parallel increases in exercise levels during treatment. The high degree of association observed between self-efficacy ratings and actual exercise levels provides strong support for the self-efficacy theory postulating that success experiences are effective means of increasing selfefficacy expectancies.

Dolce et al (78) observed that the post-treatment selfefficacy ratings of patients with chronic pain correlated significantly with exercise levels, reduction in medication use and work status at follow-up periods ranging from six to 12 months. Dolce et al (78) suggested that, if self-efficacy expectancies are related to improvement, then patients who do not increase their perceptions of self-efficacy, despite other post-treatment advances, are likely candidates for relapse.

Council et al (79) reported results similar to those of Dolce et al (78). They noted that the actual physical performance of patients with back pain was best predicted by self-efficacy ratings that appeared to be determined by pain response expectancies. These results suggest that the daily pain experience determines pain response expectancies for specific movements, and pain response expectancies appear to influence performance and associated pain behaviour through their effects on efficacy expectancies. These findings also indicate that pain response expectancies associated with specific movements are based on generalized expectancies drawn from daily experiences, and suggest that patients with chronic pain have well-established ideas that are incorporated into schemata as to how much pain they will experience in different situations. As noted above, anticipation of pain can greatly inhibit actual behavioural performance, thereby contributing to disability.

Lorig et al (77) found that pretreatment scores on a measure of self-efficacy for pain functioning and symptoms 
were associated negatively with pain, disability and depression for patients with rheumatoid arthritis at the fourmonth follow-up. In addition, increases in self-efficacy have been associated with improvements in depression, pain and disability $(80,81)$.

All of the studies reviewed suggest that self-efficacy plays a particularly important role in the perception of and adjustment to pain and subsequent disability. What mechanisms account for the observed association between selfefficacy and behavioural outcome? Cioffi (82) suggested that at least four psychological processes could be responsible. For example, because perceived self-efficacy decreases anxiety and its concomitant physiological arousal, the patient may approach the task with less potentially distressing physical information to begin with; the efficacious person is able to willfully distract attention from potentially threatening physiological sensations; the efficacious person perceives and is distressed by physical sensations, but simply persists in the face of them (stoicism); and physical sensations are neither ignored nor necessarily distressing but, rather, are relatively free to take on a broad distribution of meanings (change interpretations).

There are several ways in which perceived coping efficacy can provide relief from pain. People who believe that they can alleviate suffering likely mobilize whatever ameliorative skills that they have learned and persevere in their efforts. Patients who doubt their ability to control their pain are likely to give up readily in the absence of quick results. A sense of coping efficacy also reduces distressing anticipations that create aversive physiological arousal and bodily tension, which only exacerbate pain sensation and discomfort. Bandura (71) further suggested that techniques that enhance mastery experiences the most are the most powerful tools for bringing about behavioural change. He proposed that cognitive variables are the primary determinants of behaviour, but that these variables are most effectively influenced by performance accomplishments. The results described above appear to support Bandura's prediction.

\section{OPERANT CONDITIONING}

In the operant model, behavioural manifestations of pain, rather than pain per se, are central (83). When a person is exposed to a stimulus that causes tissue damage, the immediate response is to withdraw and attempt to escape from noxious sensations. This may be accomplished by avoiding an activity believed to cause or exacerbate pain, seeking help to reduce symptoms and so forth. These behaviours are observable and, consequently, subject to the principles of operant conditioning.

The operant view proposes that acute 'pain behaviours', such as limping to protect a wounded limb from producing additional nociceptive input, may come under the control of external contingencies of reinforcement and, thus, develop into a chronic pain problem. Pain behaviours (eg, complaining, inactivity) may be positively reinforced directly, for example, by attention from a spouse or health care provider (see responses of the family of the patient described in the present article). Pain behaviours may also be maintained by the escape from noxious stimulation, through the use of drugs or rest, or the avoidance of feared or undesirable activities (eg, work). In addition, 'well behaviours' (eg, activity, working) may not be sufficiently reinforcing, and the more rewarding pain behaviours may, therefore, be maintained. The pain behaviour originally elicited by organic factors may become, at least in part, a response to reinforcing environmental events. Because of the actual and anticipated consequences of specific behavioural responses, it is proposed that pain behaviours may persist long after the initial cause of the pain is resolved or greatly reduced. The central feature of the operant model is that behaviours have consequences and the consequences, real or anticipated, maintain the behaviours.

\section{CONCLUSIONS}

The diathesis-stress model proposed suggests that predisposing factors interact with exposure to a trauma, and set in motion a range of cognitive and behavioural processes. In particular, the following factors were included within the model: anxiety sensitivity, anticipation of pain, catastrophizing ideation, attributions about the cause of symptoms and worries about the future, self-efficacy, fear-avoidance beliefs and operant conditioning. This set of factors may be key to understanding the persistence of physical disability in chronic stages of low back pain, whiplash-associated disorders, cumulative trauma disorders and fibromyalgia syndrome. It is important to emphasize that these factors interact with the trauma and any related physical pathology. Thus, this does not suggest that physical factors are unimportant, rather that these conditions and people with these conditions are viewed within a biobehavioural perspective $(84,85)$. Some clinical data described support various components of the diathesis-stress model.

Some people, despite injury and pain, resume their usual activities in due time and recover. According to the diathesis-stress model, persistent pain and disability may develop from, and be exacerbated and maintained by, the interaction of predisposing factors (diathesis) and threatening environmental events (stress). Thus, a person who is emotionally reactive and fear-prone (diathesis) may be more likely to acquire avoidance responses following a physical trauma (a fear-producing stressor).

The diathesis-stress model emphasizes the role of learning in the onset, exacerbation and maintenance of pain in patients with persistent pain problems. A range of factors, both physical (eg, physical pathology) and psychological (eg, anxiety sensitivity, negative affectivity), have been suggested to predispose people to developing chronic pain (84); however, the predisposition is necessary but not sufficient. In addition to cognitive factors (ie, anticipation, causal attributions, expectations), fear and harm avoidance, and contingencies of reinforcement are of central importance. Conditioned reactions are viewed as being self-activated on the basis of learned expectations, as well as being automatically evoked. The critical factor in the model, 
therefore, is not that events occur together in time, but that people learn to predict them and to summon the appropriate reactions. It is the individual patient's processing of information that results in anticipatory anxiety and avoidance behaviours. These cognitive factors, along with operant ones, maintain chronic pain and disability.

The diathesis-stress perspective on pain management focuses on providing patients with techniques to reduce fear by graded exposure and counterconditioning, helping them to gain a sense of control over the effects of pain on their life, as well as actually modifying sensory facets of the experience and reinforcement contingencies. Behavioural experiences help to show patients that they are capable of more than they assumed, increasing their sense of personal competence while reducing their avoidance of activity due to fear of injury or harm. Cognitive techniques help to place affective, behavioural, cognitive and sensory responses under the patient's control. Long term maintenance of behavioural changes may occur only if the patient has learned to attribute success to his or her own efforts. The results of several investigations $(23,54,78)$ have shown that these treatments can result in changes in beliefs about pain, coping style and reported pain severity, as well as in direct behavioural changes. Further, treatment that results in increases in perceived control over pain and decreases in catastrophizing are also associated with decreases in pain severity ratings and functional disability $(73,74)$, and changes in physiological activity (31).

Additional research is warranted to test each of the proposed links in the diathesis-stress model. Specifically, are each of the constructs essential for understanding chronic pain and disability following perceived traumas? How do the extent and specific characteristics of the trauma account for the percentage of variance? What role, if any, does a prior traumatic experience have on susceptibility to fear avoidance? How do anxiety sensitivity and catastrophizing develop? Are they genetic or learned styles based on prior experience, including observational learning? How does anxiety sensitivity relate to somatization? Studies should evaluate the role of additional features to broaden the model. For example, what is the role of social support in mediating or moderating fear avoidance? Are people at risk for chronicity hypersensitive to sensory input or only noxious stimulation?

The clinical implications of the diathesis-stress model should also be investigated. Can people at risk for disability be identified based on the constructs proposed? What role do health care providers play in reinforcing appraisal and beliefs associated with disability? What can these health care providers do to prevent the evolution of disability? If anxiety sensitivity is a predisposing factor, how modifiable is it? If it is modifiable, what would be the most efficient means of intervening? Preliminary data $(33,54)$ have been presented indicating that exposure is an effective means of treatment for patients with chronic pain, but can these methods be used to prevent disability in samples 'at risk?' Finally, the role that post-traumatic stress disorder may play in fear avoidance also deserves attention.

ACKNOWLEDGEMENTS: Preparation of this manuscript was supported in part by grants from the National Institute of Arthritis and Musculoskeletal and Skin Diseases (AR/AI44724, AR47298) and the National Institute of Child Health and Human Development (HD33989).

\section{REFERENCES}

1. Burton AK, Tillotson KM, Main CJ, Hollis S. Psychosocial predictors of outcome in acute and subacute low back trouble. Spine 1995;20:722-8.

2. Waddell G, Main CJ. Chronic backache, distress, illness, behaviour and surgery. Acta Orthop Belg 1987;53:265-8.

3. Waddell G, Newton M, Henderson I, Somerville D, Main CJ. A Fear Avoidance Beliefs Questionnaire (FABQ) and the role of fearavoidance beliefs in chronic low back pain and disability. Pain 1993;52:157-68

4. Gatchel RJ, Polatin PB, Mayer TG. The dominant role of psychosocial risk factors in the development of chronic low back pain disability. Spine 1995;20:2702-9.

5. Hasenbring M, Ulrich HW, Hartmann M, Soyka D. The efficacy of a risk factor-based cognitive behavioral intervention and electromyographic biofeedback in patients with acute sciatic pain. An attempt to prevent chronicity. Spine 1999;24:2525-35.

6. Turk DC. Transition from acute to chronic pain: role of demographic and psychosocial factors. In: Jensen TS, Turner JA, Wiesenfeld-Hallin Z, eds. Proceedings of the 8th World Congress in Pain Research and Management. Seattle: IASP Press, 1997:185-213.

7. Wallis BJ, Lord SM, Bogduk N. Resolution of psychological distress of whiplash patients following treatment by radiofrequency neurotomy: a randomized, double-blind, placebo-controlled trial. Pain 1997;73:15-22.

8. Gatchel RJ, Gardea MA. Psychosocial issues. Their importance in predicting disability, response to treatment, and search for compensation. Neurol Clin N Am 1999;17:149-66.

9. Turk DC. Cognitive factors in chronic pain and disability. In: Craig KD, Dobson K, eds. Advances in Cognitive-behavioral Therapy. Thousand Oaks: Sage 1996:83-115.

10. Reiss S, McNally RJ. The expectancy model of fear. In: Reiss S, Bootzin RR, eds. Theoretical Issues in Behavior Therapy. New York: Academic Press, 1985:107-21.

11. Asmundson GJ, Norton GR. Anxiety sensitivity in patients with physically unexplained chronic back pain: a preliminary report. Behav Res Ther 1995;33:771-7.

12. Asmundson GJG, Taylor S. Role of anxiety sensitivity in pain-related fear and avoidance. J Behav Med 1996;19:577-86.

13. Asmundson GJG, Norton PJ, Norton GR. Beyond pain: the role of fear and avoidance in chronicity. Clin Psychol Rev 1999;19:97-119.

14. Linton SJ, Buer N, Vlaeyen JWS, Hellsing A-L. Are fear-avoidance beliefs related to the inception of an episode of back pain: a prospective study. Psychol Health 2000;14:1051-9.

15. Vlaeyen JWS, Kole-Snijders AM, Boeren RGB, van Eek H. Fear of movement/(re)injury in chronic low back pain and its relation to behavioral performance. Pain 1995;62:363-72.

16. Jensen MP, Romano JM, Turner JA, Good AB, Wald LH. Patient beliefs predict patient functioning: Further support for a cognitive-behavioral model of chronic pain. Pain 1999;81:94-104.

17. Stroud MW, Thorn BE, Jensen MP, Boothby JL. The relation between pain beliefs, negative thoughts, and psychosocial functioning in chronic pain patients. Pain 2000;84:347-52. 
18. Turner JA, Jensen MP, Romano JM. Do beliefs, coping, and catastrophizing independently predict functioning in patients with chronic pain? Pain 2000;85:115-25.

19. Anderson KO, Dowds BN, Pelletz RE, Edwarts WT, Peeters-Asdourian C. Development and initial validation of a scale to measure self-efficacy beliefs in patients with chronic pain. Pain 1995;63:77-84.

20. Williams DA, Robinson ME, Geisser ME. Pain beliefs: assessment and utility. Pain 1994;59:71-8.

21. Buckelew SP, Parker JC, Keefe FJ, et al. Self-efficacy and pain behavior among subjects with fibromyalgia. Pain 1994;59:377-84.

22. Jacob MC, Kerns RD, Rosenberg R, Haythornthwaite J. Chronic pain: intrusion and accommodation. Behav Res Ther 1993;31:519-27.

23. Tota-Faucette ME, Gil KM, Williams DA, Keefe FJ, Goli V. Predictors of response to pain management treatment. The role of family environment and changes in cognitive processes. Clin J Pain 1993;9:115-23.

24. Wall PD. On relation of injury to pain. Pain 1979;6:253-64.

25. Pennebaker JW. The Psychology of Physical Symptoms. New York: Springer, 1982.

26. Rachman S, Levitt K, Lopatka C. Panic: the links between cognitions and bodily symptoms. Behav Res Ther 1987;25:411-23.

27. Vlaeyan JWS, Linton SJ. Fear-avoidance and its consequences in chronic muculoskeletal pain: a state of the art. Pain 2000;85:317-32.

28. Crombez G, Vervaet L, Lysens R, Eelen P, Baeyerns F. Do pain expectancies cause pain in chronic low back patients? A clinical investigation. Behav Res Ther 1996;34:919-25.

29. Fordyce W, Lansky D, Calsyn D. Pain measurement and pain behavior. Pain 1984;13:53-69.

30. Asmundson GJG, Kuperos JN, Norton GR. Do patients with chronic pain selectively attend to pain-related information: preliminary evidence for the mediating role of fear. Pain 1997;72:27-32.

31. Flor H, Turk DC, Birbaumer N. Assessment of stress-related psychophysiological responses in chronic back pain patients. J Consult Clin Psychol 1985;53:354-64.

32. Burns JW, Wiegner S, Derleth M, Kiselica K, Pawl R. Linking symptom-specific physiological reactivity to pain severity in chronic low back pain patients: a test of mediation and moderation models. Health Psychol 1997;16:319-26.

33. Vlaeyen JWS, Seelen HAM, Peters M, et al. Fear of movement/(re)injury and muscular reactivity in chronic low back pain patients: an experimental investigation. Pain 1999;82:297-304.

34. Feuerstein M, Beattie P. Biobehavioral factors affecting pain and disability in low back pain: mechanisms and assessment. Phys Ther 1995; 75:267-9.

35. Keefe FJ, Zuck S, Opiteck J, Hage E, Dalrymple L, Blumenthal J. Pain in arthritis and musculoskeletal disorders: The role of coping skills training and exercise interventions. J Sports Phys Ther 1996;24:279-90

36. Lenthem J, Slade PD, Troup JDG, Bentley G. Outline of a fearavoidance model of exaggerated pain perception - I. Behav Res Ther 1983;21:401-8.

37. McCracken LM, Gross RT, Sorg PJ, Edmands TA. Prediction of pain in patients with chronic low back pain: effects of inaccurate prediction and pain-related anxiety. Behav Res Ther 1993;31:647-52.

38. Crombez G, Vervaet L, Lysens R, Eelen P, Baeyerns F. Avoidance and confrontation of painful, back straining movements in chronic back pain patients. Behav Modif 1998;2:62-77.

39. Crombez G, Vlaeyen JW, Heuts PH. Pain-related fear is more disabling than pain itself: evidence on the role of pain-related fear in chronic back pain disability. Pain 1999;80:329-39.

40. Vlaeyen JWS, Kole-Sniders A, Rooteveel A, Ruesink R, Heuts P. The role of fear of movement/(re)injury in pain disability. J Occup Rehabil 1995;5:235-52.

41. Turk DC, Okifuji A. What factors affect physicians' decisions to prescribe opioids for chronic noncancer pain patients? Clin J Pain 1997;13:330-6.

42. Mayer TG, Gatchel RJ. Functional Restoration for Spinal Disorders: The Sports Medicine Approach. Philadelphia: Lea \& Febiger, 1988.

43. Hildebrandt J, Pfingsten M, Saur P, Jansen J. Prediction of success from a multidisciplinary program for chronic low back pain. Spine 1997;22:990-1001.
44. Klenerman L, Slade PD, Stanley IM, et al. The prediction of chronicity in patients with an acute attack of low back pain in a general practice setting. Spine 1995;4:345-56.

45. Himmelstein JS, Feuerstein M, Stanek EJ, et al. Work-related upper extremity disorders and work disability: clinical and psychosocial presentation. J Occup Environ Med 1995;37:1278-86.

46. Mathis LB, Gatchel RJ, Polatin PB, Boulas HJ, Kinney RK. Prevalence of psychopathology in carpal tunnel syndrome patients. J Occup Rehabil 1994:4:199-210.

47. Borkan J, Reis S, Hermoni D, Biederman A. Talking about the pain: a patient-centered study of low back pain in primary care. Soc Sci Med 1995;40:977-88.

48. Skelton AM, Murphy EA, Murphy RJL, O'Dowd TC. Patients' views of low back pain and its management in general practice. Br J Gen Pract 1996;46:153-6.

49. Al-Obaidi SM, Nelson RM, Al-Awadhi S, Al-Shuwaie N. The role of anticipation and fear of pain in the persistence of avoidance behavior in patients with chronic low back pain. Spine 2000;25:1126-31.

50. Keen S, Dowell AC, Hurst K, Moffett JAK, Tovey P, Williams R. Individuals with low back pain: how do they view physical activity? Fam Pract 1999;16:39-45.

51. McCracken LM, Gross RT. The role of pain-related anxiety reduction in the outcome of multidisciplinary treatment for chronic low back pain: preliminary results. J Occup Rehabil 1998;8:179-89.

52. Davey G. Phobias: A Handbook of Theory, Research and Treatment. Chichester: Wiley, 1997.

53. Linton SJ, Bradley LA, Jensen I, Spangfort E, Sundell L. The secondary prevention of low back pain: a controlled study with follow-up. Pain 1989;36:197-207.

54. Vlaeyen JWS, de Jong J, Geilen M, Heuts PHTG, Van Breukelen G. Graded exposure in vivo in the treatment of pain-related fear: a replicated single-case experimental design in four patients with chronic low back pain. Behav Res Ther 2001;39:151-66.

55. McCracken LM, Gross RT. Does anxiety affect coping with chronic pain? Clin J Pain 1993;9:253-9.

56. Crombez G, Vlaeyen JWS, Heuts PHTG, Lysens R. Pain-related fear is more disabling than pain itself: evidence on the role of pain-related fear in chronic back pain disability. Pain 1999;80:329-39.

57. Eccleston C, Crombez G, Aldrich S, Stannard C. Attention and somatic awareness in chronic pain. Pain 1997;72:209-15.

58. Flor H, Turk DC. Chronic back pain and rheumatoid arthritis: predicting pain and disability from cognitive variables. J Behav Med 1988;11:251-65.

59. Sullivan MJL, Edgley K, Mikail S, Dehoux E, Fisher R. Psychological correlates of health care utilization in chronic illness. Can J Rehabil 1992;6:13-21

60. Turner JA, Clancy S. Strategies for coping with chronic low back pain: relationship to pain and disability. Pain 1986;24:355-64.

61. Flor H, Behle DJ, Birbaumer N. Assessment of pain-related cognitions in chronic pain patients. Behav Res Ther 1993;31:63-73.

62. Turk DC, Holzman AD. Chronic pain: interfaces among physical, psychological, and social parameters. In: Holzman AD, Turk DC, eds. Pain Management: A Handbook of Psychological Treatment Approaches. New York: Pergamon Press, 1986:1-9.

63. Hodge JR. The whiplash neurosis. Psychosomatics 1971;12:245-9.

64. Lee J, Giles K, Drummond PD. Psychological disturbances and an exaggerated response to pain in patients with whiplash injury. J Psychosom Res 1993;37:105-10.

65. Turk DC, Okifuji A. Perception of traumatic onset, compensation status, and physical findings: impact on pain severity, emotional distress, and disability in chronic pain patients. J Behav Med 1996;19:435-53.

66. Hadler N. Fibromyalgia: la maladie est morte. Vive le malade! J Rheum 1997;24:1250-1; discussion 1252.

67. Reilly PA. How should we manage fibromyalgia? Ann Rheum Dis 1999;58:325-6.

68. DeGood DE, Kiernan B. Perception of fault in patients with chronic pain. Pain 1996;64:153-9.

69. Tsushima W, Stoddard V. Ethnic group similarities in the biofeedback treatment of pain. Med Psychother 1990;3:69-75. 
70. Dolce JJ, Doleys DM, Raczynski JM, Lossie J, Poole L, Smith M. The role of self-efficacy expectancies in the prediction of pain tolerance. Pain 1986;27:261-72.

71. Bandura A. Self-efficacy: toward a unifying theory of behavior change. Psychol Rev 1977;84:191-215.

72. Turk DC, Meichenbaum D, Genest M. Pain and Behavioral Medicine: A Cognitive-behavioral Perspective. New York: Guilford Press, 1983.

73. Jensen MP, Turner JA, Romano JM. Self-efficacy and outcome expectancies: relationship to chronic pain coping strategies and adjustment. Pain 1991;44:263-9.

74. Jensen MP, Turner JA, Romano JM, Karoly P. Coping with chronic pain: a critical review of the literature. Pain 1991;47:249-83.

75. Spinhoven P, Ter Kuile MM, Linssen ACG, Gazendam B. Pain coping strategies in a Dutch population of chronic low back pain patients. Pain 1989;37:77-83.

76. O'Leary A, Shoor S, Lorig K, Holman HR. A cognitive-behavioral treatment for rheumatoid arthritis. Health Psychol 1988;7:527-44.

77. Lorig K, Chastain RL, Ung E, Shoor S, Holman HR. Development and evaluation of a scale to measure perceived self-efficacy in people with arthritis. Arthritis Rheum 1989;32:37-44.
78. Dolce JJ, Crocker MF, Moletteire C, Doleys DM. Exercise quotas, anticipatory concern and self-efficacy expectancies in chronic pain a preliminary report. Pain 1986;24:365-75.

79. Council JR, Ahern DK, Follick MJ, Kline VL. Expectancies and functional impairment in chronic low back pain. Pain 1988;33:323-31

80. Keefe FJ, Affleck JC, Lefebvfre JC, Starr K, Caldwell DS, Tennen H. Pain coping strategies and coping efficacy in rheumatoid arthritis: a daily process analysis. Pain 1997;69:35-42.

81. Smarr KL, Parker JC, Wright GE, et al. The importance of self-efficacy in rheumatoid arthritis. Arthritis Care Res 1997;10:18-26

82. Cioffi D. Beyond attentional strategies: a cognitive-perceptual model of somatic interpretation. Psychol Bull 1991;109:25-41.

83. Fordyce WE. Behavioral Methods for Chronic Pain and Illness. St Louis: Mosby, 1976.

84. Flor H, Birbaumer N, Turk DC. The psychobiology of chronic pain. Adv Behav Res Ther 1990;12:47-84.

85. Turk DC, Flor H. Chronic pain: A biopsychosocial perspective. In: Gatchel RJ, Turk DC, eds. Psychosocial Factors in Pain: Critical Perspectives. New York: Guilford Press, 1999:18-34. 


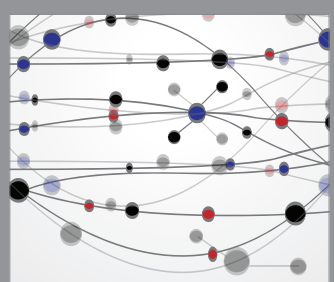

The Scientific World Journal
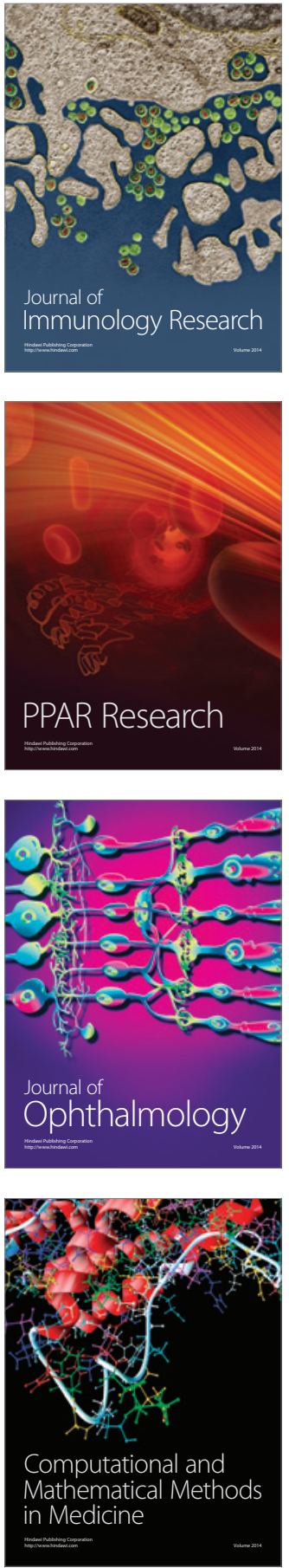

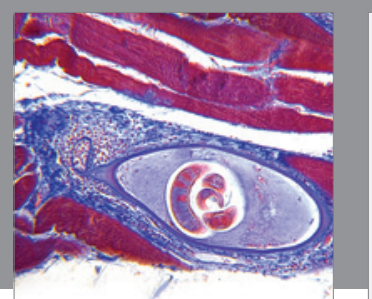

Gastroenterology Research and Practice

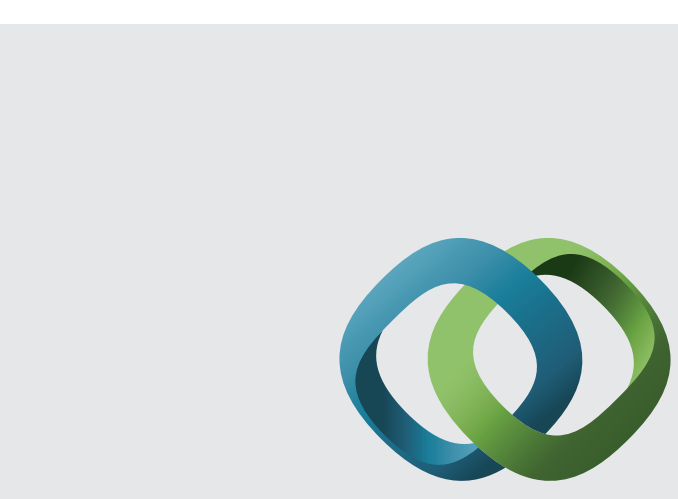

\section{Hindawi}

Submit your manuscripts at

http://www.hindawi.com
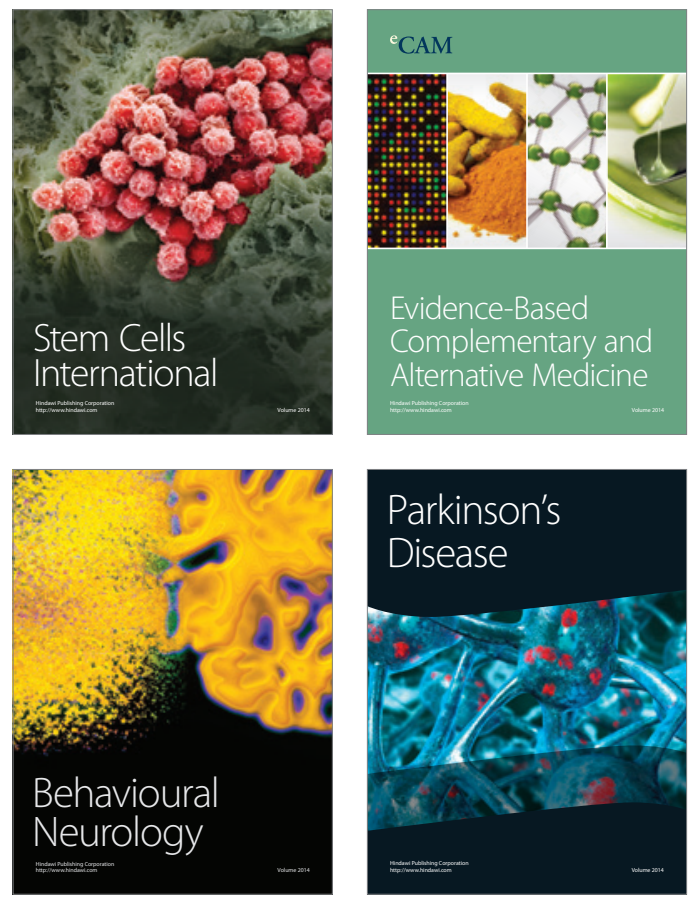
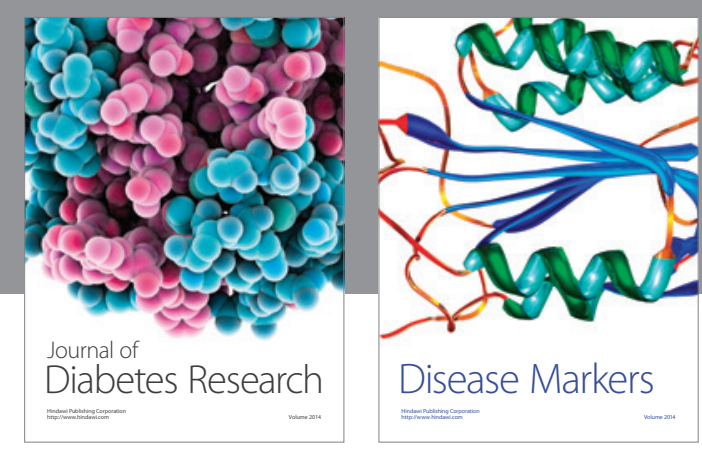

Disease Markers
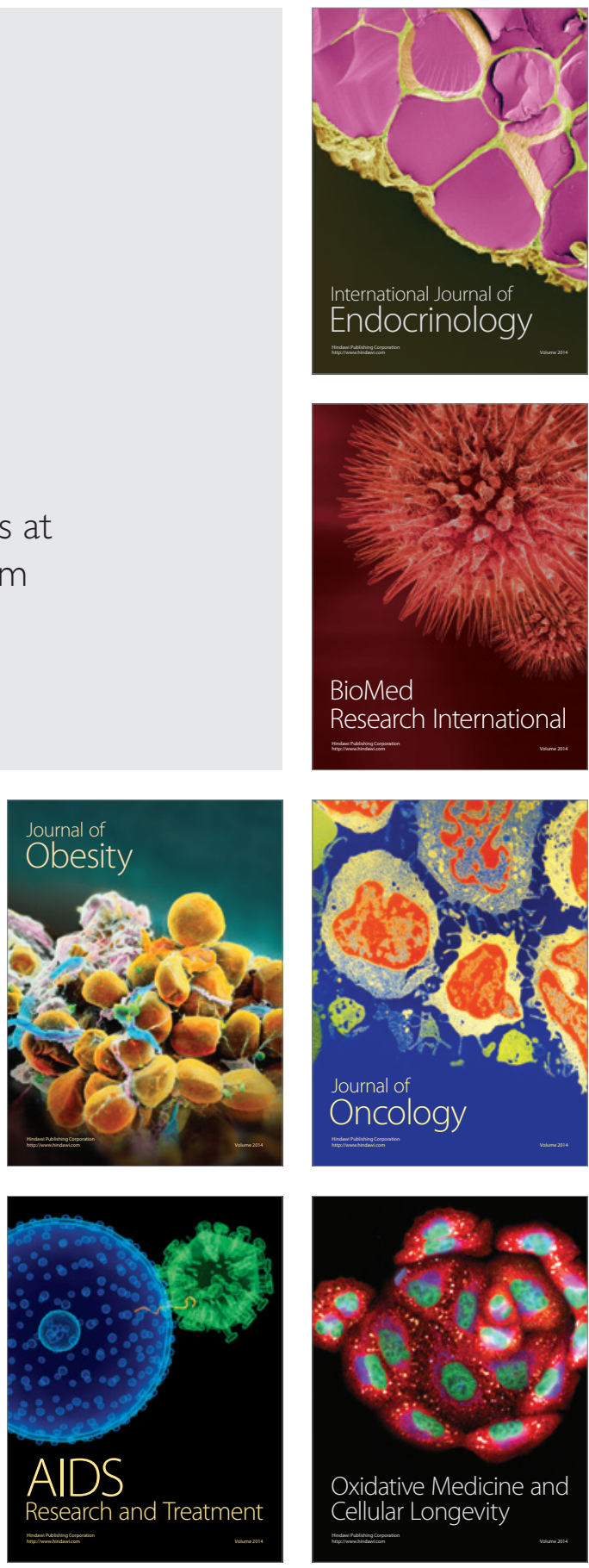